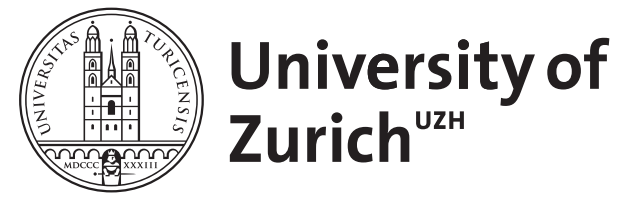
Archive

University of Zurich

University Library

Strickhofstrasse 39

CH-8057 Zurich

www.zora.uzh.ch

Year: 2016

\title{
On Peirce's claim that belief should be banished from science
}

Gaultier, Benoit

DOI: https://doi.org/10.2979/trancharpeirsoc.52.3.06

Posted at the Zurich Open Repository and Archive, University of Zurich

ZORA URL: https://doi.org/10.5167/uzh-187310

Journal Article

Published Version

Originally published at:

Gaultier, Benoit (2016). On Peirce's claim that belief should be banished from science. Transactions of the Charles S. Peirce Society, 52(3):390-415.

DOI: https://doi.org/10.2979/trancharpeirsoc.52.3.06 


\section{On Peirce's Claim that Belief Should Be Banished from Science}

Author(s): Benoit Gaultier

Source: Transactions of the Charles S. Peirce Society, Vol. 52, No. 3 (Summer 2016), pp. 390-415

Published by: Indiana University Press

Stable URL: http://www.jstor.org/stable/10.2979/trancharpeirsoc.52.3.06

Accessed: 22-01-2017 09:36 UTC

JSTOR is a not-for-profit service that helps scholars, researchers, and students discover, use, and build upon a wide range of content in a trusted digital archive. We use information technology and tools to increase productivity and facilitate new forms of scholarship. For more information about JSTOR, please contact support@jstor.org.

Your use of the JSTOR archive indicates your acceptance of the Terms \& Conditions of Use, available at http://about.jstor.org/terms

Indiana University Press is collaborating with JSTOR to digitize, preserve and extend access to Transactions of the Charles S. Peirce Society 


\section{On Peirce's \\ Claim that Belief Should Be Banished from Science}

Benoit Gaultier

\section{Abstract}

In this article I examine the ground and validity of Peirce's claim that "belief has no place in science". Contrary to the general view, such a claim should not be understood as merely an overreaction to William James' thesis that there can be legitimate non-evidential reasons to believe. For Peirce, believing that something is the case implies, at least when believing takes a certain form, a kind of dogmatism incompatible with the proper conduct of inquiry towards truth. In this paper, I examine two ways in which Peirce argues for the "no belief in science" thesis. I first discuss 'his claim that belief is incompatible with the "Will to Learn". Peirce argues that believing that $p$ in such a way that one does not have any real doubts about whether $p$ implies that one has a dogmatic attitude vis-à-vis possible future evidence that not- $p$; I claim that this anticipates the line of reasoning that supports Kripke's "paradox of dogmatism". After having indicated how they can both be resisted, I examine a second waywhich seems to have been overlooked in Peirce scholarship - in which the founder of pragmatism argues for the "no belief in science" thesis. Peirce often relates this thesis to his view of abduction and the nature of explanatory hypotheses: the conclusion of an abductive inference is not, and should not be, the belief that a given explanatory hypothesis $\mathrm{H}$ is true, probably true, or likely to be true, but rather that $\mathrm{H}$ is such that it is a possible explanation of fact $\mathrm{F}$.

Keywords: Charles Peirce, Belief, Dogmatism, Fallibilism, Abductive Hypotheses, Kripke's Paradox of Dogmatism, Bourdieu's Theory of Scientific Fields. 
Charles S. Peirce holds some views about science and inquiry whose exact significance and ratio essendi are notoriously hard to grasp. One of these is particularly intriguing, namely, his frequently inferring from the intuitive ideas that science consists "in diligent inquiry into truth for truth's sake" (CP 1.44, c.1896), and that the greatest threat to science is to "block the way of inquiry" (CP 1.135, RLT $178,1898)$, the conclusions that "belief $[\ldots]$ has no place in science" and that the "scientific man", when inquiring, has only "provisional" opinions (CP 1.635, RLT 112, 1898). In this article, I examine the ground and validity of the infamous and, arguably, strongly counterintuitive thesis that "belief has no place in science". By so doing, I will show that, contrary to what is generally admitted-even by many Peirce scholars - such a claim should not be understood merely as an overreaction to the views William James advances in The Will to Believe (James 1897), where he argues for the legitimacy of nonevidential, or practical, reasons to believe. In his writings, Peirce defends the "no belief in science" thesis in three ways that are not completely unrelated but that nonetheless involve different lines of reasoning. What is common to all of them is the idea that believing that something is the case involves, at least when belief takes a certain form, a kind of dogmatism that is incompatible with the proper conduct of inquiry towards truth.

In what follows I present and examine two of these three lines of reasoning, and I shall set aside, for reasons of space, the one I find least convincing: Peirce's argument that belief is to be excluded from science because true scientists are, as scientists, interested only in truth, not in the success of any action, and identify themselves with the "unlimited community" of inquiring minds. I first study Peirce's most straightforward way of arguing for the thesis that belief has no place in scientific activity: belief is incompatible with the "Will to Learn", because the Will to Learn supposes "a dissatisfaction with one's present state of opinion" (CP 5.583, RLT 171, 1898) that belief, at least when it takes a certain form, excludes $(\$ 1)$. In this section, I shall defend two claims: first, I shall argue, following Hookway $(2000 ; 2012)$, that it is hard to understand how the practice of inquiry could go on if belief were to be entirely banished from science. Second, after indicating why I find it unconvincing to defend the plausibility of the "no belief in science" thesis by distinguishing two different forms of belief_-one that should be excluded from science because it goes with dogmatically closing down inquiry concerning a given question, and another that is not detrimental to the advance of science because it does not go with this-I shall argue for the following: we should not accept Peirce's reasoning that believing that $p$ in such a way that one is ready to act upon this belief and does not have any real doubts about whether $p$ implies that one 
has, vis-à-vis possible future evidence that not- $p$, a dogmatic attitude that one would not have if one had not believed that $p$ in such a way. The comparison I shall make between Peirce's line of reasoning on this issue and Saul Kripke's "paradox of dogmatism" (Kripke 2011) should make this point clear.

After that, I shall examine a third way-one that seems to have been overlooked in Peirce scholarship—in which the founder of pragmatism argues for the "no belief in science" thesis: rather than directly arguing that (a certain form of) belief dogmatically closes inquiry, Peirce often relates his thesis that belief has no place in science to his view of abduction and the nature of explanatory hypotheses: the conclusion of an abductive inference is not, and should not be, the belief that a given explanatory hypothesis $\mathrm{H}$ is true, probably true, or likely to be trueeven if, at the same time, $\mathrm{H}$ is taken to be a "plausible" explanation of some fact $\mathrm{F}$ - but rather that $\mathrm{H}$ is such that it is a possible explanation of F. Accordingly, if, according to Peirce, the belief that $\mathrm{H}$ is true has no place in science, this does not mean that one should have, vis-à-vis the proposition that $\mathrm{H}$ is true, a doxastic attitude other than belief, or a particular kind of belief, but rather that one should have a belief about whether or not $\mathrm{H}$ could be true. And I shall indicate why having beliefs with such a content is not detrimental to the pursuit of truth-contrary to believing that $\mathrm{H}$ is true (but for reasons that are distinct from those rejected in $\$ 1)(\$ 2)$.

Finally, by relying on Pierre Bourdieu's theory of scientific fields, I shall contend that the predominant interest in truth that is, according to Peirce, required in order for science to be properly conducted does not necessarily imply any "heroism of self-sacrifice" (CP 2.654, W $3: 284,1878$ - - by which I mean sacrificing one's own practical interests, however personally important they are, to the collective and indefinite pursuit of truth $(\$ 3)$.

1.

Peirce's most straightforward argument for the thesis that belief has no place in science is that belief is incompatible with the "Will to Learn" because "the first thing that the Will to Learn supposes is a dissatisfaction with one's present state of opinion" (CP 5.583, RLT 170-171, 1898). Now, according to Peirce, this kind of dissatisfaction is intrinsically correlated to the state of doubt that belief opposes and pacifies. Believing that $p$ leads, for its part, to dismissing as "unserious" the possibility that not-p-which leads one who believes that $p$ to close her mind to the question of whether or not it is true that $p$, and so to not be in a position to re-examine this question, whatever the facts and objections to which one might later be exposed. Now, since such an attitude amounts to a form of dogmatism incompatible with the advance and progress of inquiry, Peirce concludes that belief should be 
banished from science. The purpose of this section is to examine this line of reasoning.

For Peirce, "it is not knowing, but the love of learning, that characterizes the scientific man": "If a man burns to learn and sets himself to comparing his ideas with experimental results in order that he may correct those ideas, every scientific man will recognize him as a brother, no matter how small his knowledge may be" (CP 1.44, c.1896). In other words, for an inquiry to be a real inquiry, or a real scientific inquiry, it has to be carried out while being "devoured by a desire to find things out" (CP 1.8, c.1897), "to penetrate into the reason of things" (CP 1.44 , c.1896). Now, according to Peirce, this state is impossible when one believes that one's theories or hypotheses are true.

More specifically:

[H]olding for true is of two kinds; the one is that practical holding for true which alone is entitled to the name of Belief, while the other is that acceptance of a proposition which in the intention of pure science remains always provisional. To adhere to a proposition in an absolutely definitive manner $[\ldots]$ amounts simply to not wishing to learn. Now he who does not wish to learn cuts himself off from science altogether.

Upon this first, and in one sense this sole, rule of reason, that in order to learn you must desire to learn, and in so desiring not be satisfied with what you already incline to think, there follows one corollary which itself deserves to be inscribed upon every wall of the city of philosophy.

Do not block the way of inquiry. (RLT 178, 1898)

So, instead of having beliefs, scientists must provisionally and detachedly accept or adopt theories and hypotheses and "struggle [...] to see the errors" of such pseudo-beliefs (CP 6.3, 1898). According to Peirce, this would not be possible if they really believed their hypotheses to be true, since if one believes that $p$, one can have only "paper doubts" about the truth of $p$. Because "the scientific man is above all things desirous of learning the truth" and, correlatively, does not lose sight of our inescapable fallibility, he cannot, and must not, have real beliefs; he "ardently desires to have his present provisional beliefs (and all his beliefs are merely provisional) swept away, and will work hard to accomplish that object" (ibid.).

In this regard, Peirce writes that "the provisional establishment" of "doctrines" or theories in "pure theoretical science" is, "[c] ompared with living belief [...] nothing but a ghost" (CP 5.60, 1903); that holding that a proposition or hypothesis is true is not, in pure science, "what is properly and usually called belief, that is, the adoption of a

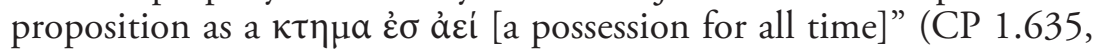


RLT 112, 1898); or that scientists only "postulate" or "hope" that such-and-such a theory is true-which "does not make it true, nor so much as afford the slightest rational motive for yielding it any credence" (CP 6.39, W 8:113, 1892). The reason why scientists accept a hypothesis, write it in "the list of premisses [they] propose... to use" (CP 1.635, RLT 112, 1898), or receive it "as a scientific result" (CP $7.163,1901)$, is that "the predictions [deductively] based upon it are verified" by "facts not taken into account in the formation of the hypothesis" (ibid.). It is, in other words, "the economy of endeavor [that] prescribes that, for the time being, further inquiry shall cease" about the hypothesis in question (CP 5.589, RLT 178, 1898). More generally, the decision that scientists make to submit certain hypotheses to the verdict of experience-which supposes the provisional acceptance of some other hypotheses and experimental proceduresis grounded on considerations of "economy of research", not on their judging the hypotheses under examination as likely or as "extremely probable" (CP 1.120, c.1896); they can even be judged "almost wildly incredible" (ibid.).

From this perspective, according to Christopher Hookway, including a hypothesis "in the list of 'established truths' to be used in formulating new theories and in constructing experiments" does not consist for Peirce in believing that hypothesis, but in making a "practical judgment", and this

involves no commitment to the probable or approximate truth of the proposition: ceasing testing this proposition at this stage of inquiry will be the best means of making progress eventually towards the truth. [...] It is now good to treat the world as if this proposition is true; but we have no right to believe that it actually is true. (Hookway 2000: 39)

The problem with this view is that saying that the acceptance of a given hypothesis follows from a "practical judgment" relative to considerations about the regulation of the scientific activity seems simply to amount to saying that its acceptance follows from a belief about how to proceed to attain truth as rapidly as possible, given the hypotheses at hand. Why then would the reasons mentioned by Peirce for excluding belief from science not apply to such a "practical judgment"? If we believe that a given hypothesis should not, for the advance of inquiry, be once again put to the test but, on the contrary, be written on the list of those upon which we can submit other hypotheses to the verdict of experience, the following seems to ensue, according to Peirce's line of reasoning: we cease to wish to learn anything about the role that should be given to the hypothesis in question in the regulation of inquiry. But then this hypothesis becomes as fixed as if we had directly believed it, 
since it is on the basis of a belief that it has been written in the list of hypotheses that are to be used as premises of scientific inquiry.

It could be objected that the "practical judgments" in question are not of the same nature as real beliefs and so are not "extra-scientific" (CP 5.589, RLT 177, 1898): they are themselves suppositions, or provisionally accepted hypotheses, relative to the regulation of inquiry. The problem with this objection is that even if it is of course possible to accept or to suppose that $p$ without considering that $p$ is clearly established or supported by the available evidence-i.e., without believing that $p$-it is nonetheless true that this supposition involves, as with any supposition, a belief: the belief that making the supposition that $p$ is the best thing to do given, among other things, the aim of scientific inquiry, the available evidence, and considerations relative to the economy of research. As a consequence, to fill science with suppositions cannot sever it from beliefs; and, conversely, to sever inquiry from beliefs comes down to severing it from suppositions.

How, then, should we understand Peirce's claim that belief has no place in science? Hookway envisages the following possibility:

In pure scientific research, we may still 'act' on the basis of scientific beliefs, by using them in designing experiments or in planning observations, even if we would not use them as guides to action in connection with practical matters. Laboratory actions are one thing, and actions that shape everyday life or matters of personal importance are another. How we act depends upon the risks we are ready to take and the goals we have. (Hookway 2012:13n)

For Hookway, we can either think that such "scientific beliefs" are not real beliefs, because beliefs are habits of action whose scope is not restricted to laboratories, or we can think that they are real beliefs but deny that beliefs are such habits of action (ibid.:202). The problem is that, whichever we choose, the following question remains open: what exactly does the doxastic attitude that scientists should have vis-à-vis the hypotheses that are involved in their inquiries consist in? By exactly what doxastic attitude should belief be replaced in scientific inquiry if, as I have just pointed out, it cannot be made of suppositions all the way down?

It could be said that the partisan of the "no belief in science" thesis does not have to answer this question, because, in actual fact, this thesis means neither that belief should be replaced by another kind of doxastic attitude (like supposition, or acceptance, for instance), nor that any form of belief should be excluded from scientific inquiry. It rather means that the type of belief that consists in a full doxastic commitment vis-à-vis a given proposition has no place in science because it "impedes and discourages honest, fruitful investigation" (Migotti 2005:53); and 
it means that the "provisional, quasi-belief of scientific inquiry" is not detrimental to the advance of science because it goes with a thirst for truth that leads the scientific believer to recognize that future scientific developments might prompt her to change her views (ibid.:54). According to Mark Migotti, "while a scientist "ought to be in a double state of mind about [a promising] hypothesis, at once ardent in his belief that so it must be, and yet not committing himself further than to do his best to try the experiment' ([R] 175), a true believer [...] will be resolutely single-minded, irrevocably committed to the propositions he believes" (ibid.:45-6). This line of thought also appears in the following crucial passage:

[T] here are certain inferences which, scientifically considered, are undoubtedly hypotheses and yet which practically are perfectly certain. Such for instance is the inference that Napoleon Bonaparte really lived at about the beginning of this century, a hypothesis which we adopt for the purpose of explaining the concordant testimony of a hundred memoirs, the public records of history, tradition, and numberless monuments and relics. [And yet i]t would surely be downright insanity to entertain a doubt about Napoleon's existence. [...] [A]s Science progresses $[\ldots]$ it is $[\ldots]$ entitled to reflect: this ground [that is: this scientific conclusion] has held a long time without showing signs of yielding. I may hope that it will continue to hold for a great while longer. This reflection, however, is [...] extra-scientific. For Practice, however, it is vitally important $[\ldots$ because $]$ there is now reason to believe in the theory, for belief is the willingness to risk a great deal upon a proposition. (CP 5.589, RLT 176-177, 1898)

The main difficulty with this position is that it seems to take for granted what in fact has to be explained: how an historian can have no real doubts at all, just like any other person of sound mind, that Napoleon Bonaparte really lived-i.e., how she can believe that this is an established truth "to which no competent man today demurs" (CP 1.635, RLT 112, 1898) — and, at the same time, believe, as an historian, that this is an hypothesis and that future experience might reveal that Napoleon did not exist. According to Cheryl Misak, Peirce's view is that a scientist "ought to be in a double state of mind" because she "must believe, but be constantly aware that her belief might be overturned" (Misak 2004b:162). Her awareness of human fallibility — that is, of the fact that every one of our beliefs might be false, and that we might be "compelled to deny" tomorrow what we "cannot doubt today"-will not lead her to doubt that Napoleon really lived, and it is not a reason for her to do so. But its being indubitable for her that Napoleon really lived-in Peirce's terminology, her "substantial" or "practical" certainty that he really lived-does not mean that she is "absolutely certain" about it; for this would come down to taking her belief that he really lived to be 
infallible. Thus, her "general sense of human fallibility" (R 329, c.1904, cit. in Misak 2004a:55) affects her certainty that Napoleon really lived by preventing it from being "absolute" (see Misak 2004a:50-55). In short, for Peirce, according to Misak, "[b]elief is not out of place in science-it is just tempered by fallibilism" (Misak 2004b:162).

However, it is doubtful that, when it comes to understanding why believing that something is the case does not necessarily imply a form of dogmatism incompatible with the pursuit of truth, this line of reasoning is really satisfactory:

a) if the fact that one's belief that Napoleon really lived is tempered by fallibilism simply consists in its being tempered by one's awareness that the falsity of the belief is a logical, but not serious, possibility;

b) if, as a consequence, this awareness leaves unaffected one's take on whether Napoleon really lived-in other words, if it cannot lead one to have any real doubts about whether he really lived;

c) and if it is one's having no real doubts about whether Napoleon really lived that is supposed to have problematic dogmatic consequences for the pursuit of truth;

it follows that:

d) the fact that one's belief that Napoleon really lived is tempered by fallibilism, in the sense indicated in (a), does not imply that one's belief does not have problematic dogmatic consequences for the pursuit of truth.

In order to develop and get a better grasp on this point, let us consider the view defended by Migotti (2005). Migotti seems to suggest that if one does not really doubt that Napoleon really lived, one cannot directly see the question of whether Napoleon really lived as remaining open; not doubting that Napoleon really lived means, for him as for Peirce, that one takes inquiry to be closed concerning the question at issue. But one can indirectly take the question of whether Napoleon really lived to remain open. This is because one's not having real doubts about it does not prevent one from believing that, since one is a fallible epistemic agent, it is very likely that some of one's many interconnected beliefs about European history are false; and there is no reason why the belief that Napoleon really lived, as one of these interconnected beliefs, could not be proven to be so by an evolution of one's system of beliefs about European history. But in fact, following this line of thought cannot really lead one to believe that inquiry is not closed concerning the question at issue-assuming that, before following this line of thought, one had closed it by (fully) believing that Napoleon really lived. In effect, that Napoleon really lived does not cease to be (fully) believed by following this line of thought. What one realizes by following it is 
rather that this belief, like any of one's interconnected (full) beliefs about European history, whatever their content, could turn out to be false, because of one's fallibility. In other words, one's mind is still completely made up about whether Napoleon really lived; it is just that, by ignoring, or not focusing on, the content of one's belief that Napoleon really lived and by merely considering this belief as-like all of one's beliefs - the doxastic product of one's fallible cognitive capacities, one cannot take it to be unerringly correct and reliable. But one's opinion about whether Napoleon really lived remains untouched. Now, assuming with Peirce that, by (fully) believing that Napoleon really lived, one believes that inquiry on this issue is closed, it follows that merely recognizing one's own global fallibility cannot lead one to cease to believe that inquiry is closed on whether Napoleon really lived.

It could then be concluded from the foregoing that the only way for belief not to be detrimental to inquiry is if believing that $p$ does not mean not having real doubts about whether $p$. But this would come down to saying that, for any proposition one could inquire into and believe (that is, for any empirical proposition at least), one should never dismiss as "unserious" the possibility that the proposition is false. This is implausible, and it is certainly not Peirce's view on beliefs such as the one that Napoleon really lived, or that the earth is round.

In the rest of this section, I will show why it is unnecessary to banish belief from scientific inquiry in a different - and, in my opinion, more convincing - way than Misak and Migotti: there is no reason to adopt the "no belief in science" thesis because it is possible to contest from the outset Peirce's inference that if one's (fully) believing that $p$ involves disregarding as unserious the logical possibility that not- $p$, then this belief leads to dogmatism vis-à-vis the question whether $p$ and thus impairs one's tracking of the truth. Let us start with Isaac Levi's view that, contrary to what Peirce contends, I can, on the one hand, fully believe that $p$ and set aside as unserious the possibility that not- $p$, and, on the other, not dismiss as unserious or merely logical the possibility that new pieces of evidence might appear in the future that would lead me to truly and justifiably believe that it is not the case that $p$. This is not to say that, given the evidence that is now available to me, I can really or seriously believe that $p$ might be false; it is to say that I can really believe that I might come to correctly believe that $p$ is false on the basis of evidence that is not currently available (or on the basis of further reflection on the evidence that I now have, and that I now believe to support $p$ ). In Levi's words:

$\mathrm{X}$ can consistently rule out the logical possibility that there is no ink bottle before him as a serious possibility while, at the same time, recognizing as a serious possibility that future experience may warrant X's withdrawing this judgment. (Levi 2012:229) ${ }^{1}$ 
Levi's position on this issue is strikingly similar to that of Kripke:

I may be in no doubt now as to whether there is an ink-bottle in front of me and yet it seems to me compatible with this to suppose that future evidence could persuade me that there is no ink-bottle. There seem to me to be two different questions here: whether I have the kind of certainty characterized by there being no doubt now, and whether I take the attitude that no future evidence could disprove this. (Kripke 2011:42)

And being certain at $t^{l}$ that there is an ink-bottle before him, not merely believing that this is highly probable, also means, according to Kripke, that he is "equally certain" at $t^{l}$ that he will not learn in the future that some extraordinary events were taking place at $t^{l}$ in virtue of which that belief was false-for instance, that he was deceived by a clever magician (ibid.:41n). Not being certain of this would mean, for Kripke, not being certain that there is an ink-bottle before him. At first sight, there might seem to be a tension between what Kripke is "equally certain" of, and his "suppos[ing] that future evidence could persuade [him] that there is no ink-bottle". But, in fact, supposing this simply consists in not excluding the logical possibility that the proposition in question could turn out to be false, not in taking this possibility to be, in Peircean terms, a serious one.

What may seem more problematic is how being certain that there is an ink-bottle before one-and, correlatively, that one will not encounter in the future evidence to the effect that there was no ink-bottle before one-could be of no consequence for one's doxastic attitude visà-vis evidence of the contrary if one were to encounter some. Peirce's argument that belief has no place in science, that a scientist should not be "perfectly cocksure that he knows already", because, if he believed his conclusions, this would prevent him from "stand[ing] ready to abandon one or all as soon as experience opposes them" (CP 1.635, c.1896; CP 1.55, RLT 112, 1898), remarkably anticipates Kripke’s "paradox of dogmatism". Here is how it can be stated: if one believes that it is true that $p$, one is committed to believing that any evidence against $p$ one might encounter would be misleading since it would be evidence against something that is true; therefore, if one believes that it is true that $p$, one is committed to believing that any evidence against $p$ one might encounter should be disregarded — which is strongly counterintuitive. In Kripke's words, if one believes that $p$, "one could conceivably resolve that, if one is faced, regardless of whether one wanted it, with particular evidence against $p$, one should nevertheless ignore it" (Kripke 2011:44). Yet, one "should rationally leave [oneself] open to changings-of-mind" due to future evidence, whatever the epistemic status of one's belief that $p$ (ibid.:45). 
The paradox is usually stated in terms of knowledge: if a) one knows that $p$ is true, and b) one knows that if $p$ is true then any evidence against $p$ one might encounter would be misleading, then c) one knows that any evidence against $p$ one might encounter would be misleading. This is, as Gilbert Harman puts it, "paradoxical, because I am never in a position simply to disregard any future evidence though I do know a great many different things" (Harman 1973:148). ${ }^{2}$ However, when the "paradox" is stated in this way and is thus taken to be a paradox of knowledge-as Kripke initially states it—it is easy to overlook what Kripke himself takes to be his main point: why exactly is it unacceptable to make "in advance", as a consequence of one's believing that it is true that $p$, the "resolution [...] to ignore certain types of evidence" (Kripke 2011:48)? More specifically, why is it unacceptable if this resolution directly follows from the conclusion that any evidence against $p$ one might encounter would be misleading, which itself seems to directly follow from one's believing that it is true that $p$ ? Now, this question is not about the conclusion to which one is committed or that one is entitled to draw in case one's belief that $p$ is true or amounts to knowledge; it is about the conclusion to which one is committed or that one is entitled to draw from one's believing that it is true, or known, that $p .{ }^{3}$

Kripke's paradox is that when, given the evidence I have, I believe that it is true that $p$, I am committed to believing that any evidence against $p$ I might encounter would be misleading and so should be disregarded. So, why should I take the risk of exposing myself to new evidence relative to whether $p$, since, at best, I will not lose something I already have: a true belief about whether $p$ ? Why should I not form the "intention to avoid epistemic harm by closing [my] mind" (Sosa 2014:80)? What goes wrong in the reasoning that leads to this conclusion is that it implicitly presupposes that, from the triviality that if it is the case that $p$, then all things that could be taken to be evidence that not-p are misleading, it follows that if one (fully) believes that it is the case that $p$, then one believes that all things that could be taken to be evidence that not-p are misleading. In other words, the reasoning at play in Kripke's paradox implicitly relies on the following inference: from the triviality that if it is the case that $p$, then any evidence that not-p is misleading, it follows that if one (fully) believes that it is the case that $p$, then one (fully) believes that any evidence that not-p is misleading. But this inference is by no means indisputable. Here is how, in a Peircean spirit, it is possible to resist it - and thus, how it is possible to neutralize both Kripke's paradox and Peirce's claim that if a scientist (fully) believed her conclusions, this would lead to a form of dogmatism that would prevent her from "stand[ing] ready to abandon one or all as soon as experience opposes them". When, at $t^{l}$, I (fully) believe, or, alternatively, do not have real doubts that, given the evidence I have-i.e., given the things I take to 
be facts-it is the case that $p$, I am committed to (fully) believing that it won't be discovered that things are such that, if I took them, now at $t^{l}$, to be part of the evidence I have-i.e., to be facts-I would cease to (fully) believe that $p$. When I (fully) believe that $p$, I am committed to (fully) believing that such things will not be discovered. But believing this, or being committed to believing it, implies neither a) that I believe, or commits me to believing, that such things could not be discovered, nor b) that if such things were discovered, I would be misled by them if I were to count them as evidence that not- $p$ and thus cease to (fully) believe that $p$.

In short: to (fully) believe that $p$ is to (fully) believe (or to be committed to (fully) believing) that evidence that not- $p$ will not be faced; it is not to (fully) believe that, logically, physically, or metaphysically, this cannot happen. When I (fully) believe that $p$, I (fully) believe (or am committed to fully believing) that it could happen but that it will not happen. As such, from one's (fully) believing that one will not be faced with evidence that not- $p$, one cannot draw any conclusions about the attitude one should have vis-à-vis such evidence if this were to happen. (Fully) believing that I will not be faced with evidence that not- $p$ is not (or does not commit me to) believing that, if this were to happen, I would be misled, contrary to (fully) believing that it cannot happen: (fully) believing that it cannot happen is (or commits me to) believing that if this were to happen-if I took such and such a thing to be evidence that not- $p$-I would be misled by those things.

It therefore appears that (fully) believing that something is the case does not imply that one has, vis-à-vis possible future evidence that not-p, a dogmatic attitude (that one would not have if one had not believed that $p$ ) consisting in not standing "ready to abandon one or all as soon as experience opposes them" (CP 1.635, RLT 112, 1898), an attitude one would have if (fully) believing that $p$ implied believing that any possible future evidence that not- $p$ would be misleading evidence. In fact, (fully) believing that $p$ given evidence $\mathrm{E}$ at $t^{l}$ does not even prevent one from (fully) believing that some new non-misleading evidence $\mathrm{E}^{*}$ might appear at $t^{2}$ that would correctly lead one to revise one's belief that $p$. It is true, however, that (fully) believing that $p$ closes one's inquiry about whether $p$; as Peirce holds, one cannot have no real doubts that $p$ and, at the same time, take the question of whether $p$ to remain open. But this is not really detrimental to one's personally tracking the truth, or to scientific inquiry, because of a) one's being constantly exposed to new evidence, and b) the high interconnectedness of beliefs_-and of scientific ones in particular. Indeed, even if, apropos anything one (fully) believes to be the case, one takes inquiry to be closed on the matter at issue, this does not prevent one-as we have just seen-from changing beliefs 
when faced with counterevidence that one (fully) believed one would not face. Moreover, one's ceasing to inquire into whether $p$ as soon as one (fully) believes that $p$ will not stop one from going on to inquire into related issues and trying to obtain evidence enabling one to elucidate them; and this will often result in the acquisition of evidence (at least partly) relevant to the issue of whether $p$ - which might well be evidence that not- $p$.

In order to be entitled to claim that (full) beliefs are fundamentally detrimental to the advance of science toward truth, Peirce needs to show that they tend to be irremovable, not subject to being abandoned "as soon as experience opposes them" (ibid.), and that the only function they allow empirical data to play is, not guiding (and, possibly, refuting), but confirming them. But the argument that one's (fully) believing that $p$ leads one to be insensitive to any evidence that not- $p$ one could be faced with, because (fully) believing that $p$ commits one to disregarding such evidence as misleading, is unsatisfactory and thus does not succeed in showing that beliefs naturally tend to be irremovable. In other words, it does not succeed in establishing that believing that $p$ given evidence $\mathrm{E}$ prevents one from doubting that $p$ when one is faced with new evidence $\mathrm{E}^{*}$ - where $\mathrm{E}^{*}$ would lead rational individuals who have not previously formed the belief that $p$ to believe that not- $p$ given $E^{*}$. Therefore, this argument, which is also at the center of Kripke's paradox, cannot rationally ground the "no belief in science" thesis.

\section{2.}

I will now examine a second way-that, as far as I know, has been overlooked in Peirce scholarship—in which the founder of pragmatism argues for the "no belief in science" thesis: rather than directly arguing that belief dogmatically closes inquiry, Peirce often relates his thesis that belief has no place in science to his view of abduction and the nature of explanatory hypotheses.

Let us begin with one of Peirce's last, and more enlightening, definitions of retroduction:

By Retroduction I mean that kind of reasoning by which, upon finding ourselves confronted by a state of things that, taken by itself, seems almost or quite incomprehensible, or extremely complicated if not very irregular, or at least surprising, we are led to suppose that perhaps there is, in fact, another definite state of things, because, though we do not perceive any unequivocal evidence of it, nor even of a part of it (or independently of such evidence if it does exist), we yet perceive that this supposed state of things would shed a light of reason upon the state of facts with which we are confronted, rendering it comprehensible, likely (if not certain), or comparatively simple and natural. (R 856:3-4) 
In a retroductive inference like "the surprising fact, $\mathrm{C}$, is observed; but if A were true, C would be a matter of course" (CP 5.189, 1903), one can only infer "that a certain state of things may be true" (NEM $3: 204,1911)$. The ground of this inference is that one "either fully perceives or more or less suspects that the perplexing phenomenon would be a necessary or quite probable consequence" (CP 8.229, c.1910) of the possible state of affairs A (or H). "There is no probability about it $[\mathrm{H}]$. It is a mere suggestion which we tentatively adopt [...] for the sake of its explanation of known facts." (RLT 142, 1898) It "is something which looks as if it might be true and were true" (CP 1.120, c.1896).

On account of this [possible] Explanation, the inquirer is led to regard his conjecture, or hypothesis, with favor. As I phrase it, he provisionally holds it to be "Plausible" [...]. The whole series of mental performances between the notice of the wonderful phenomenon and the acceptance of the hypothesis, [...] the remarking of its smooth fitting to the anomaly, as it is turned back and forth like a key in a lock, and the final estimation of its Plausibility [...], I term Retroduction [...].

[But r] etroduction does not afford security. The hypothesis must be tested. (CP 6.469, 1908)

It is important here to note that the "plausibility" of $\mathrm{H}$, as it has been defined, does not mean that $\mathrm{H}$ is true, probably true, or likely to be true. Contrary to what Peirce sometimes suggests, its plausibilitydue to its being perceived as being such that it could explain F (either immediately, or after "the remarking of its smooth fitting to the anomaly, as it is turned back and forth like a key in a lock") —is not even a "reason to suspect that $[\mathrm{H}]$ is true" (CP 5.189, 1903). $\mathrm{H}$ is "plausible", or regarded "with favor", only in the sense that $\mathrm{H}$ is seen (either immediately, or after having reflected on it very carefully) as being a possible explanation of F. Such a "plausibility" is "sufficient to warrant further examination" of $\mathrm{H}$ (NEM 3:204, 1911) — that is, to send it off to experimental trial.

However, Peirce also writes that its plausibility constitutes "a reason for accepting the Retroductive conclusion" because "man must trust to his power of getting at the truth" (ibid). How can we understand such an idea from the perspective I have indicated? And how can we understand the related idea-which Peirce claims on many occasions - that one simply wouldn't endeavor to devise and to examine explanatory hypotheses if one did not hope to be able to find the right explanation of F? Isn't this incompatible with the idea that when $\mathrm{H}$ is judged or perceived to be such that it could be the right explanation of $\mathrm{F}$, this does not amount to a reason to suspect that $\mathrm{H}$ is true-i.e., that $\mathrm{H}$ is the right explanation of $\mathrm{F}$ ? 
There is no incompatibility. The fact that "man must trust to his power of getting at the truth" ("simply because it is all he has to guide him", Peirce adds) simply means that one must trust one's judgment that $\mathrm{H}$ is such that it is a possible explanation of $\mathrm{F}$; or, equivalently, that one must consider one's judgment a reliable guide to truth about the question of whether $\mathrm{H}$ could be the right explanation of $\mathrm{F}$. This does not mean that because one judges that $\mathrm{H}$ is such that it is a possible explanation of $\mathrm{F}$, one does or has to judge that $\mathrm{H}$ is actually the right explanation of $\mathrm{F}-$ i.e., that $\mathrm{H}$ is true-or even to suspect that it is. And it is perfectly possible for one to hope that $\mathrm{H}$ is the right explanation of $\mathrm{F}$ without judging or suspecting that it is. More specifically, since one has to "trust [one's] power of getting at the truth", one's perceiving $\mathrm{H}$ as being a possible explanation of $\mathrm{F}$ entitles one to hope that $\mathrm{H}$ is the right explanation of $\mathrm{F}$, which would not be the case if one had judged that $\mathrm{H}$ was not a possible explanation of $\mathrm{F}$.

Two related issues then arise. 1) Does deciding to send $\mathrm{H}$ off to experimental trial necessarily imply wanting to know whether $\mathrm{H}$ is the right explanation of $\mathrm{F}$ (and not just whether $\mathrm{H}$ could be the right explanation of F)? Is this the raison d'être of putting $\mathrm{H}$ to test? 2) Is the only thing we can learn from sending $\mathrm{H}$ off to experimental trial the probability of H's being the right explanation of F?

As I have already underlined, for Peirce "retroduction does not afford security" (CP 6.469, 1908). "There is no probability about $[\mathrm{H}]$. It is a mere suggestion which we tentatively adopt [...] for the sake of its explanation of known facts" (RLT 142, 1898). "It is something which looks as if it might be true and were true" (CP 1.120, c.1896). So when Peirce adds that "the [plausible] hypothesis must be tested" (CP 6.469, 1908), the reader might naturally be tempted to think that $\mathrm{H}$ should be tested with the objective of determining how probable it is that $\mathrm{H}$ is true-i.e., how probable it is that $\mathrm{H}$ is the right explanation of $\mathrm{F}$. However, this cannot be Peirce's view about the scientific role of experimental trials, since he writes in a decisive passage part of which I have already quoted:

As Science progresses [... one] is entitled to reflect: this ground [that is: this "scientific conclusion"] has held a long time without showing signs of yielding. I may hope that it will continue to hold for a great while longer. This reflection, however, is [...] extra-scientific. [...] As Practice apprehends it, the conclusion no longer rests upon mere retroduction, it is inductively supported. For a large sample has now been drawn from the entire collection of occasions in which the theory comes into comparison with fact, and an overwhelming proportion, in fact all the cases that have presented themselves, have been found to bear out the theory. And so, says Practice, I can safely presume that so it will be with the great bulk of the cases in which I shall go upon the theory; especially as they will closely resemble 
those which have been well tried. In other words there is now reason to believe in the theory [...]. But this belief is no concern of science [...]. Those retroductive inferences which at length acquire such high degrees of certainty, so far as they are so probable are not pure retroductions and do not belong to science, as such, while so far as they are scientific and are pure retroductions, have no true probability and are not matters for belief. We call them in science established truths, that is, they are propositions into which the economy of endeavor prescribes that for the time being further inquiry shall cease. (CP 5.589, RLT 177-178)

Why, then, from a purely scientific point of view, might a scientist want to test a "plausible" explanatory hypothesis? What could be learned from an experimental trial, and only from an experimental trial, about the question of whether the hypothesis tested is a good one, but, at the same time, not about its being (probably) true or not?

To this question, the Peircean answer is rather simple: one is in a position to learn from the experimental testing of $\mathrm{H}$ whether one was wrong in thinking that $\mathrm{H}$ is such that it could be the right explanation of $\mathrm{F}$. If $\mathrm{H}$ does not pass the test of experience, then (supposing one admits the verdict of experience) $\mathrm{H}$ cannot be a possible explanation of $\mathrm{F}$ and so has to be rejected. This point appears most clearly when Peirce writes that abduction is reasoning of the following form:

If $\mathrm{A}$ is true, $\mathrm{C}\{$ is not/is $\}$ true

But $\mathrm{C}\{$ is not/ is $\}$ true

Therefore, Is A not true?

Instead of "interrogatory", the mood of the conclusion might more accurately be called "investigand", and be expressed as follows: "It is to be inquired whether A is not true." (L 463, 1905) ${ }^{6}$

The imperative element of the conclusion of an abductive inference ("It is to be inquired whether...") is related to the idea that "man must trust to his power of getting at the truth" (my emphasis)—i.e., one must trust one's judgment that $\mathrm{H}$ is such that it is a possible explanation of $\mathrm{F}$ - so that $\mathrm{H}$ deserves to be put to the test. This is why, as Bellucci and Pietarinen remark, an abductive inference does not simply "present a given hypothesis for contemplation" (2015:357). The negative element of the conclusion ("... whether A is not true" (my emphasis)) makes it clear that the role of experimental testing is not to decide whether the hypothesis in question is (probably) true but to determine whether it really is a possible explanation of F. Its being rejected by experience would condemn $\mathrm{H}$ as not being a possible explanation. That the focus of an abductive inference is on possibility, and that inquiring, by means of experimental testing, into whether $H$ is false is not just a 
way, in Peirce's view, of inquiring into whether $H$ is true, is also visible in another aspect of the conclusion of such an inference: its being interrogative. From a Peircean point of view, the main problem with expressing the conclusion of an abductive inference by "Is A not true?" is not the interrogative mood (which explicitly indicates that the conclusion is about whether $\mathrm{H}$ is a possible explanation of $\mathrm{F}$ ), but the fact that, so expressed, it does not contain the imperative element that explicitly appears in "It is to be inquired whether A is not true".

When $\mathrm{H}$ ("A") is tested and not judged to be refuted by experience, one can draw from each experimental trial the conclusion that $\mathrm{H}$ remains a possible explanation of $\mathrm{F}$ (" $\mathrm{C}$ ") — in other words, remains "plausible", or such that it could be true. In this regard, the experimental testing of $\mathrm{H}$ fulfils a similar function as noticing $\mathrm{H}$ 's "smooth fitting to the anomaly, as it is turned back and forth like a key in a lock". The difference is that $\mathrm{H}$ can be considered, after having survived the test of experience, a "scientific result" (CP 7.163, 1901), ${ }^{7}$ because, when asked (so to speak), the world did not object to the scientist's judgement that $\mathrm{H}$ was "plausible". She is then entitled to rely on $\mathrm{H}$ in her scientific activity in general and in her retroductive reasonings in particular.

More specifically, even though she was already entitled, before putting $\mathrm{H}$ to the test, to regard her judgment as a reliable guide to truth about the question of whether $\mathrm{H}$ could be the right explanation of $\mathrm{F}$, the world is put, by $H$ itself, in the role of arbiter about the possibility of $\mathrm{H}$ as an explanation of $\mathrm{F}$. That is so because if $\mathrm{H}$ is a properly conceived explanatory hypothesis, part of its content consists in specifying that if a certain kind of event $E$ were not the case in a certain kind of circumstance $\mathrm{C}$, this would be incompatible with H's being the case. Thus, a central part of putting $\mathrm{H}$ to the test can be characterized as endeavoring to bring about $\mathrm{C}$ (or conditions relevantly similar to $\mathrm{C}$ ) and observing whether or not $\mathrm{E}$ (or something relevantly similar to $\mathrm{E}$ ) happens.

It is important to note that this is not to say that $H$ is more "plausible", in Peirce's sense, after having survived the test: it cannot be more or less the case that $\mathrm{H}$ is such that it could explain $\mathrm{F}$ - either $\mathrm{H}$ constitutes a possible explanation of $\mathrm{F}$ or it does not. One may be unsure, or have no clear view about the issue, but $\mathrm{H}$ cannot become a better explanation of $\mathrm{F}$ in virtue of its having survived the test of experience. ${ }^{8}$ After having failed to pass such a test, it appears that $\mathrm{H}$ simply cannot be a possible explanation of $\mathrm{F}$ (supposing that the verdict of experience is admitted). If it does not make sense to say that $\mathrm{H}$ is more plausible after having survived the test of experience, is it nevertheless possible to claim that, after having survived it, it is more likely that $\mathrm{H}$ is a possible explanation of F? It is possible to claim this, but only in the sense that the world did not prove wrong-on the basis of conditional 
expectations that are part of the content of $\mathrm{H}$ - the retroductive inference that $\mathrm{H}$ is a possible explanation of $\mathrm{F}$. And a critical point is that judgments about whether or not $\mathrm{H}$ is a possible explanation of $\mathrm{F}$ (or about how likely or probable it is that $\mathrm{H}$ is so) are not judgments about whether or not $\mathrm{H}$ is the right explanation of $\mathrm{F}$ (or about how likely or probable it is that $\mathrm{H}$ is so). Correlatively, believing that $\mathrm{H}$ is such that it could be the right explanation of $\mathrm{F}$ clearly does not entail believing that $\mathrm{H}$ is the right explanation of $\mathrm{F}$. It does not even entail supposing such a thing. Crucially, believing that $\mathrm{H}$ is such that it could be the right explanation should not be confused with supposing or guessing that $\mathrm{H}$ is the right explanation.

If $\mathrm{H}$ "is inductively supported" by its not having been refuted by experience on many occasions, one is perfectly "entitled" (CP 5.589, RLT 177, 1898), says Peirce, to draw the conclusion that $\mathrm{H}$ (probably) is the right explanation of $\mathrm{F}$ - that is, entitled to believe (that it is probable) that $\mathrm{H}$ actually explains F. Correlatively, one is then entitled to base one's actions on H. Nevertheless, this conclusion is for Peirce "extra-scientific", because scientific inquiry consists only of inferences and conclusions about whether a certain hypothesis could be the right explanation of F. Even if hoping to find the truth about the question of whether $\mathrm{H}$ (or $\mathrm{H}^{*}$, or $\mathrm{H}^{* *}$, etc.) is the right explanation of $\mathrm{F}$ is constitutive of scientific inquiry, this does not imply that scientific inquiry cannot but consist, at certain times at least, of inferences and conclusions about whether a certain hypothesis is the right explanation of F: eliminating "plausible" possible explanations of $\mathrm{F}$ is the proper way of endeavoring to find out the only possible explanation of F-which, if successful, is nothing but having found the right explanation of $\mathrm{F}^{\text {? }}$

It might be objected that if the core of Peirce's view about the scientific attitude one should adopt towards explanatory hypotheses is as I have described, it does not follow-quite the contrary, in fact - that belief has no place in science, against what Peirce repeatedly claims: after all, if my interpretation is correct, one is allowed, even as a scientist, to judge or believe (before or after having sent it to experimental trial) that $\mathrm{H}$ is such that it could be the right explanation of $\mathrm{F}$. In other words, the attitude scientists should take towards an explanatory hypothesis $\mathrm{H}$ does not consist in having an alternative kind of doxastic attitude to belief vis-à-vis the question of whether $\mathrm{H}$ is true or probably true-something weaker, more detached, like acceptance or supposition, for instance. It rather consists in wondering whether $\mathrm{H}$ is such that it could be true - that is, whether it could be the right explanation of $\mathrm{F}$ - and then in believing that $\mathrm{H}$ could be so, or could not be so. What directly concerns the "no belief in science" thesis is that because believing that $\mathrm{H}$ could be the right explanation of $\mathrm{F}$ does not exclude in any way believing that there may be other possible explanations of $F$, 
such a belief does not block the path of inquiry; unlike believing that $\mathrm{H}$ is the right explanation of $\mathrm{F}$, which fixes $\mathrm{H}$ and prevents one from reconsidering $\mathrm{H}$ in the light of new evidence (by following the Peircean line of thought I criticized in $\$ 1$ ). Therefore, while importing into scientific inquiry (legitimate, because inductively supported) beliefs about whether or not (it is probable that) $\mathrm{H}$ is the right explanation of $\mathrm{F}$ would, on Peirce's view, be detrimental to the progress of inquiry, there is no reason to be particularly worried by one's believing that $\mathrm{H}$ is such that it could be true- even if his disputable view of belief is endorsed. Accordingly, to be a good "man of science" is thus for Peirce to be able to sift out, when it comes to the conclusions one is entitled to draw from experimental trials, those that are irrelevant to, and harmful for, scientific inquiry-i.e., conclusions about whether (it is probable that) $\mathrm{H}$ is the right explanation of F; and those are not-i.e., conclusions about whether $\mathrm{H}$ could be the right explanation of $\mathrm{F}^{10}$

One might object that believing that $\mathrm{H}$ is such that it could be the right explanation of $\mathrm{F}$ also excludes, in reality, the possibility of $\mathrm{H}$ 's being false. Indeed, if $\mathrm{H}$ is false, then (trivially) $\mathrm{H}$ cannot be the right explanation of $\mathrm{F}$. Therefore, so the objection goes, believing that $\mathrm{H}$ is such that it could be the right explanation of $\mathrm{F}$ requires believing that if the results of experimental testing of $\mathrm{H}$ were found to be contrary to $\mathrm{H}$, this would not amount to a reason to reject $\mathrm{H}$. Worse still, having the belief in question implies believing that there is no point putting $\mathrm{H}$ to the test-which is patently absurd. However this objection can be easily resisted: believing that $\mathrm{H}$ is such that it could be the right explanation of $\mathrm{F}$ consists in believing that the theories and empirical evidence at hand are not incompatible with H's explaining F; more precisely, it consists in believing that they are not incompatible 1) with the explanans indicated by $\mathrm{H}$ being the case, and 2) with the idea that if $\mathrm{H}$ were true, then $\mathrm{F}$ would (probably or necessarily) follow. And this does not require_-even on Peirce's disputable view of belief — ruling out that, in the future, some new evidence might prove incompatible with H's being a possible explanation of $\mathrm{F}$.

Now, supposing that the arguments I advanced in $\$ 1$ against Peirce’s view of (full) belief as intrinsically dogmatic are correct, is there still a reason why it could be better for the advance of science to believe that (and to inquire into whether) $\mathrm{H}$ is such that it could explain $\mathrm{F}$, rather than to believe that (and to inquire into whether) $\mathrm{H}$ is the right explanation of $\mathrm{H}$ ? There is one: if it is admitted that beliefs, once formed, have the nature of habits, and that habits naturally tend to persevere in their being (to put it in Spinozian terms), it follows that beliefs naturally tend to be irrationally partly insensitive to future counterevidence, or, at least, not sensitive enough to it. This is not to say, contrary to Peirce on many occasions, that believing that $p$ implies believing that any (pseudo-)evidence that not- $p$ is misleading evidence, an unwillingness 
to learn, or a lack of "ethics of fairness and impartiality" "indissolubly bound up" with "the logic which observational science uses" —an ethics that leads real scientists "to try to see the errors of [their] beliefs", and not to try "to confirm themselves in early beliefs" (CP 6.3, 1898). This is rather to say that being a habit, which, as such, naturally tends to persevere in its being, one's believing that $p$ causally leads one not to take into account future evidence that not- $p$ in the way those who do not have any belief about whether $p$ or not- $p$ would. If this is correct, it is easy to see why it is better for the pursuit of truth to believe that $\mathrm{H}$ could explain $\mathrm{F}$, rather than to believe that $\mathrm{H}$ is the right explanation of $\mathrm{H}$ : the inertial resistance of the former belief to counterevidence does not affect one's envisaging other explanations of $F$ (but only tends to prevent one from admitting that $\mathrm{H}$ cannot be a possible explanation of F), while that of the latter directly affects it.

\section{3.}

If it is admitted, rather uncontroversially, that a) the practical interests a scientist may have in believing that $p$, interests thesatisfaction of which is independent of whether it is true that $p$, can causally lead her to believe that $p$ in cases in which, did she not have these interests, she would not have taken the evidence to (clearly) support that $p$; and that b) this impedes the advance of science towards truth, the following ensues: we would have a scientific field composed of scientists who care more about truth than about their own fate, whose predominant aim would be to be "on the path to objective truth" (CP 5.589) (and who, in this sense, would identify themselves with the scientific community), and who would permit inquiry to progress in an ideal way towards truth. This would be the case not because such an attitude would prevent these scientists from forming beliefs, but because this attitude would not prevent their beliefs from tracking the truth. In this final section, I want to examine why the predominant interest in truth that is required for science to be properly or ideally conducted does not necessarily imply, contrary to what Peirce seems to think, any "heroism of self-sacrifice" - by which I mean sacrificing one's own practical interests, however personally important they are, to the collective and indefinite pursuit of truth.

For Peirce, the scientific world is as it should be when it is "like a colony of insects, in that the individual strives to produce that which he himself cannot hope to enjoy" (CP 7.87, 1902): a scientist "does not expect to learn, in this life, what conclusion it is to which his labors are tending" (CP 7.185, 1901), because the scientific pursuit of truth is not "the work of one man's life, but as that of generation after generation, indefinitely" (CP 5.589, RLT 177, 1898). Correlatively, for Peirce, a scientist should not attribute any weight to the devastating personal consequences - in terms of career, recognition, self-esteem, etc.- of 
the falsity of a theory or hypothesis she has elaborated and to which she has devoted her life. She should stand ready to abandon this hypothesis in the light of new evidence to the same extent as any other scientist for whom its truth or falsity is of no personal practical importance, which means that she should stand ready to sacrifice her personal practical interests to the conquest of truth and should even "ardently desire" to do so (CP 6.3, 1898) when, in the presence of counterevidence to her personally consequential hypothesis, she is given the opportunity to make a step towards truth by abandoning it (see Migotti 2005:51-52). However, by relying on Pierre Bourdieu's theory of scientific fields, I would like to show that, when truth functions as an operative and regulative norm of scientific fields, a scientist's personal practical interests can, without any personal sacrifices being made, be identified with those of the scientific community and thus not be detrimental to the advance of science toward truth.

\title{
According to Bourdieu:
}

\begin{abstract}
We must resign ourselves to admitting that, short of demanding of everyone at every moment the extraordinary dispositions of the saint, the genius, or the hero, one can obtain ordinary reason or virtue only from a social order capable of making these into a specific form of well-understood self-interest. (Bourdieu 1991:22)

One does not find scientific salvation alone. Just as one is not an artist alone, but by participating in the artistic field, likewise we can say that it is the scientific field which makes scientific reason possible through its very functioning. (Bourdieu 1992:189)
\end{abstract}

For Bourdieu, scientific fields have to be organized in such a way that what they impose on and offer as a reward to their members turns out to coincide with what ideal scientists, "capable of the heroism of self-sacrifice" (in the sense indicated above) and entirely devoted to the conquest of truth, would impose upon themselves. More specifically, the scientific fields have to be organized in such a way that scientists whose personal practical interests would have prevented them, in badly-regulated scientific fields, from forming and rectifying certain beliefs (when confronted with evidence that rationally requires them to do so) are, on the contrary, spontaneously inclined to do so; this is because, in such fields, that is how their personal interests are best served.

It is important here to underline that, as members of (ideally) well-regulated scientific fields, scientists do not conduct their inquiries in this virtuous fashion because they have the intention of satisfying their personal practical interests: in such fields, they sincerely and genuinely care about the truth and rationality of their beliefs-they consider rationality to be the norm of their inquiries, and truth to be their goal. 
Bourdieu's central point is that this is so only because, in such fields, their personal interests are served only by conducting their inquiries in the way Peircean scientific heroes would conduct them-that is, by valuing disinterested truth more than anything else. To put it another way, according to Bourdieu, if reason and the universal "advance at all, it is probably because there are profits in rationality and universality, and that actions which advance reason and the universal advance at the same time the interests of those who perform them" (Bourdieu 2000 [1997]:126).

One of the main reasons that well-regulated scientific fields are able to foster truth and rationality and weaken "the ordinary antinomies between interest and reason, force and truth, etc." (Bourdieu 2004 [2001]:82) is, according to Bourdieu, their autonomy, that is, their closure upon themselves:

As the collectively accumulated scientific resources increase and, correlatively, the requirements for entry into the field are raised, de jure or de facto excluding aspirants who lack the necessary competence to compete effectively, the agents and institutions engaged in the competition tend ever more to have only the most formidable of their competitors for potential addressees or 'clients'. Their validity claims are forced to confront competing claims, also scientifically armed, to obtain recognition; the only chance for the authors of discoveries to be understood and recognized is by those of their peers who are both most competent and least prone towards indulgent complicities and therefore most inclined and qualified to engage the specific resources accumulated throughout the whole history of the field in a critique of these discoveries tending to advance reason through the power of refutations, corrections and additions. (Bourdieu 2000 [1997]:112)

I want to make two remarks about this idea. First, Robert K. Merton's ethos of science- "that affectively toned complex of values and norms which is held to be binding on the man of science", and that comprises four "institutional imperatives": "universalism, "communism', disinterestedness, and organized scepticism” (Merton 1973 [1942]:268-70)—strikingly echoes the "logical socialism" of Peirce's ethics of science:

Science is to mean for us a mode of life whose single animating purpose is to find out the real truth $[\ldots]$ and which seeks coöperation in the hope that the truth may be found, if not by any of the actual inquirers, yet ultimately by those who come after them and who shall make use of their results. (CP 7.54, c.1902)

The method of modern science is social in respect to the solidarity of its efforts. (CP 7.87, 1902) 
Second, for Merton, just as for Bourdieu, scientific ethos and scientific autonomy are "intimately intertwined" and "mutually reinforcing", as Aaron Panofsky has recently underlined. For Merton, "the freer a scientific community from extrascientific influence, the stronger its institutionalization of the ethos; and the stronger the collective commitment to elements of the scientific ethos, the less vulnerable they would be to extrascientific influences" (Panofsky 2010:141).

Nevertheless, there is for Bourdieu a certain sociological naiveté in Merton's conception of the normative power exerted by the ethos of science on members of the scientific community, which seems similar, for Merton, to that of a set of half-internalized, morally respectable rules of scientific etiquette. What is sociologically crucial for Bourdieu is that we understand the social principle of "the alchemy that transmutes the appetite for recognition into an interest for knowledge" of the purest kind; a social principle that, as a result, "enables scientific reason [...] to move progressively towards total independence from constraints and contingencies, a kind of focus imaginarius to which the rationalist conviction aspires and by which it is measured" (Bourdieu 2000 [1997]:122): a conviction which was undoubtedly also held by Peirce.

\section{Collège de France benoitgaultier@hotmail.fr}

\section{REFERENCES}

Abbreviations for the Works of C. S. Peirce

CP, followed by volume and paragraph number: Peirce (1931-1958).

NEM, followed by volume and page number: Peirce (1976)

$\mathbf{R}$ and $\mathbf{L}$, followed by manuscript number and, when available, page number: unpublished manuscripts in the Houghton Library, Harvard University. MS enumeration according to Robin (1967).

RLT, followed by page number: Peirce (1992)

W, followed by volume and page number: Peirce (1982-2010)

\section{OTHER REFERENCES}

Bellucci, Francesco, and Pietarinen, Ahti. 2015. "New Light on Peirce's Conceptions of Retroduction, Deduction, and Scientific Reasoning", International Studies in the Philosophy of Science 28, 4, pp.353-373.

Bourdieu, Pierre. 1991. "The Peculiar History of Scientific Reason", Sociological Forum 6, 1, pp.3-26.

Bourdieu, Pierre. 1992. An Invitation to Reflexive Sociology. Cambridge: Polity Press.

Bourdieu, Pierre. 2000 [1997]. Pascalian Meditations. Cambridge, Polity Press. 
Bourdieu, Pierre. 2004 [2001]. Science of Science and Reflexivity. Cambridge: Polity Press.

Harman, Gilbert. 1973. Thought. Princeton: Princeton University Press.

Hookway, Christopher. 2000. Truth, Rationality and Pragmatism: Themes from Peirce. Oxford: Oxford University Press.

Hookway, Christopher. 2012. The Pragmatic Maxim: Essays on Peirce and Pragmatism. Oxford: Oxford University Press.

James, William. 1897. The Will to Believe and Other Essays in Popular Philosophy. Reprinted in G. E. Myers (ed.) 1992, William James: Writings 1878-1899. New York: Library of America, pp.457-699.

Kripke, Saul. 2011. Philosophical Troubles. Oxford: Oxford University Press.

Levi, Isaac. 2012. Pragmatism and Inquiry. Oxford: Oxford University Press.

Merton, Robert. 1973 [1942]. "The Normative Structure of Science", in The Sociology of Science: Theoretical and Empirical Investigations. Chicago: University of Chicago Press.

Migotti, Mark. 2005. “The Key to Peirce's View of the Role of Belief in Scientific Inquiry”, Cognitio 6, 1, pp.43-55.

Misak, Cheryl. 2004a. Truth and the End of Inquiry: A Peircean Account of Truth. Oxford: Oxford University Press.

Misak, Cheryl. 2004b. "C. S. Peirce on Vital Matters", in C. Misak (ed.), The Cambridge Companion to Peirce. Cambridge: Cambridge University Press, pp.150-174.

Panofsky, Aaron. 2010. "A Critical Reconsideration of the Ethos and Autonomy of Science", in Craig J. Calhoun (ed.), Robert K. Merton: Sociology of Science and Sociology as Science. New York: Columbia University Press, pp. 140-163.

Peirce, Charles S. 1931-1958. The Collected Papers of Charles Sanders Peirce. Edited by Charles Hartshorne and Paul Weiss (vols. 1-6), and Arthur W. Burks (vols. 7-8). Cambridge, MA: Harvard University Press.

Peirce, Charles S. 1976. The New Elements of Mathematics, 4 vols. Edited by Carolyn Eisele. The Hague: Mouton.

Peirce, Charles S. 1982-2010. Writings of Charles S. Peirce: A Chronological Edition, vols.1-6, 8. Edited by the Peirce Edition Project. Bloomington and Indianapolis, IN: Indiana University Press.

Peirce, Charles S. 1992. Reasoning and the Logic of Things. Edited by Kenneth Ketner and Hilary Putnam. Cambridge, MA: Harvard University Press.

Robin, R. S. 1967. Annotated Catalogue of the Papers of Charles S. Peirce. Worcester, MA: The University of Massachusetts Press.

Sosa, Ernest. 2014. "Knowledge and Time: Kripke's Dogmatism Paradox and the Ethics of Belief”, in J. Matheson and R. Vitz (ed.), The Ethics of Belief. Oxford: Oxford University Press, pp.77-88.

\section{NOTES}

1. See also: "X can coherently fully believe that h (be absolutely certain that $\mathrm{h}$ is true, have no doubt as to the truth of $\mathrm{h}$, rule out any serious possibility that $\mathrm{h}$ is false) while recognizing the serious possibility that $\mathrm{X}$ might change $\mathrm{X}$ 's mind at some future stage of inquiry, reflection, or deliberation and do so with good reason. X's commitment to the epistemic infallibility of X's full beliefs coheres 
perfectly well with X's recognition of the revisability or corrigibility of X's full beliefs." (Levi 2012:120)

2. John Hawthorne's variant of this paradox is as follows: "Suppose there are two newspapers, The Times and The Guardian, which I trust equally well for the purposes of obtaining soccer information. With good reason: both are extremely reliable in their reporting of soccer results. I look in The Times and find a Manchester United victory reported. I trust the report. The report is in fact correct. Under such circumstances people are inclined to say I know both that The Times said that Manchester United won and also that Manchester United won. Let us suppose I also know that The Guardian will have reported a result for the Manchester United game. I deduce that either The Times and The Guardian correctly reported a Manchester United victory or else The Guardian made a mistake about the Manchester United result. Suppose, in fact that, unbeknownst to me, The Guardian did make such a mistake. People are not inclined to say I know the above disjunction" (Hawthorne 2004: 71).

3. This is why, as Kripke remarks, Harman's answer to the paradox does not address its main point. Harman's answer is that if one were to encounter evidence that not- $p$ at $t^{2}$ one would not know at $t^{2}$ that this evidence is misleading and, as such, to be disregarded. This is so because even if one knew at $t^{l}$ that $p$ and, as a consequence (according to Harman), that any evidence that not- $p$ is misleading, the latter thing would no longer be known at $t^{2}$, because, at $t^{2}$, it would no longer be known that $p$, due to one's knowledge that $p$ being undermined at $t^{2}$ by the evidence encountered at $t^{2}$ (see Harman 1973:148-149).

4. Peirce calls this kind of reasoning "retroduction", "because it starts at consequents and recedes to a conjectural antecedent from which these consequents would, or might very likely logically follow" (R 905, 1908).

5. If this is so, it is not the case that all retroductive inference consists for Peirce in "a syllogism exhibiting the surprising fact as necessarily following from the circumstances of its occurrence together with the truth of the conjecture as premises" (R 843:41, my emphasis).

6. I owe this quote to Bellucci and Pietarinen (2015).

7. "If the facts refute the hypothesis, it must be abandoned and another substituted; but if the predictions based upon it are verified, it will be entitled to be received as a scientific result until we find deductions from it which are contrary to the facts." (CP 7.163, 1901)

8. Correlatively, as Peirce remarks, the fact that $\mathrm{H}$ would explain $\mathrm{F}$ if $\mathrm{H}$ were true is something that cannot have any probability: it makes no sense to say that it is probable that if $\mathrm{H}$ is true, then $\mathrm{F}$ is "a matter of course" (CP $5.189,1903)$.

9. It could be argued that the interpretation of Peirce I defend in this paper makes his view of the nature of explanatory hypotheses and the role of experimental testing very close to Popper's, and, consequently, that it faces the same difficulties. I cannot discuss this point in detail here; I shall simply remark that a crucial difference between the two philosophers is that Peirce's view does not entail in any way the very problematic claim that induction has no real place in the logic of science. His view merely entails that because the process of scientific explanation does not involve or require believing that such and such an explanatory hypothesis is true, and because it is on the basis of induction that we can be justified in 
forming such beliefs, it follows that induction does not play a role in the process of scientific explanation that it is ordinarily thought to play.

10. This is how the following passage can be understood without our being compelled to posit an implausible (if not impossible) twofold cognitive attitude vis-à-vis the same propositions: "[T]here are certain inferences which, scientifically considered, are undoubtedly hypotheses [and so have no true probability] and yet which practically are perfectly certain [because they are "inductively supported", and so have acquired "high degrees of certainty"]. Such for instance is the inference that Napoleon Bonaparte really lived at about the beginning of this century, a hypothesis which we adopt for the purpose of explaining the concordant testimony of a hundred memoirs, the public records of history, tradition, and numberless monuments and relics. [And yet] it would surely be downright insanity to entertain a doubt about Napoleon's existence" (CP 5.589, RLT 176, 1898). 